\title{
Perancangan Kontrol Deteksi Dini Keregangan Belt Elevator Sebagai Safety Overflow Material Serbuk Biji Berbasis Programmable Logic Controller
}

\author{
Tatok Dwi Jatmiko ${ }^{1}$, Fachrudin Hunaini ${ }^{2}$, Anis Qustoniah ${ }^{3}$ \\ 1Fakultas Teknik, Jurusan Teknik Elektro, Universitas Widyagama Malang \\ ${ }^{2}$ Fakultas Teknik, Jurusan Teknik Elektro, Universitas Widyagama Malang \\ ${ }^{3}$ Fakultas Teknik, Jurusan Teknik Elektro, Universitas Widyagama Malang \\ Email: tatokdwij@gmail.com
}

\begin{abstract}
Abstrak
Elevator adalah alat distribusi vertikal material dalam industri. Dalam sistem pendistribusian material vertikal banyak masalah yang muncul, khususnya pada belt elevator. Masalah yang muncul disebabkan pemakaian belt elevator yang sudah lama dan berpotensi mengalami keregangan. Dengan kondisi itu perlu upaya pembuatan suatu sistem kontrol otomatis deteksi keregangan belt elevator berdasarkan perubahan putaran drum elevator. Disaat terjadi gangguan keregangan belt, sistem deteksi dini keregangan belt elevator berbasis PLC dapat langsung mematikan keseluruhan sistem berdasarkan perubahan nilai putaran drum atas elevator. Dengan memakai sistem gear ratio pada tiap motor penggerak, putaran chain conveyor 1 $\pm 47 \mathrm{rpm}$ dengan nilai arus $0.13 \mathrm{~A}$, kemudian unit elevator dengan putaran $\pm 98 \mathrm{rpm}$ dengan nilai arus $0.13 \mathrm{~A}$, dan terakhir putaran chain conveyor 2 menjadi $\pm 255 \mathrm{rpm}$ dengan nilai arus $0.12 \mathrm{~A}$ maka putaran disetiap unit akan berbeda nilainya sehingga dapat meminimalisir potensi terjadinya penumpukan material di setiap perpindahan unit distribusi.
\end{abstract}

Kata Kunci: Belt elevator, Deteksi putaran, Gear ratio, PLC CP1E-E3ODRA, Sensor.

\begin{abstract}
Elevator is a material vertical distribution tool in the industry. In a vertical material distribution system many problems arise, especially in elevator belts. The problem that arises is the use of an old elevator belt that has the potential to experience tension. With this condition, it is necessary to make an automatic control system for detecting the tension of elevator belts based on changes in the rotation of drum elevators. When belt tension disturbances occur, PLC-based elevator belt early detection system can immediately turn off the entire system based on changes in the drum rotation value of the elevator. By using the gear ratio system on each drive motor, chain conveyor rotation $1 \pm 47 \mathrm{rpm}$ with a current value of $0.13 \mathrm{~A}$, then the elevator unit with $\pm 98 \mathrm{rpm}$ rotation with a current value of $0.13 \mathrm{~A}$, and finally the chain conveyor 2 turns to $\pm 255 \mathrm{rpm}$ with a current value of $0.12 \mathrm{~A}$ then rotation in each unit will be of different value so as to minimize the potential for material buildup in each transfer unit distribution.
\end{abstract}

Keywords: Belt elevator, Turn detection, Gear ratio, PLC CP1E-E3ODRA, Sensor. 


\section{PENDAHULUAN}

Dalam industri transportasi dan pendistribusian material yang meliputi bahan baku serta pakanjadi sangatlah berpengaruh pada proses produksi. Pada umumnya alur produksi memanfaatkan Gaya gravitasi, material dari bawah dibawa naik ke atas kemudian diproses turun ke bawah dan seterusnya sampai proses selesai dan menghasilkan produk. Untuk membawa material yang horizontal diperlukan chain conveyor dan untuk membawa material yang mempunyai sudut dengan kemiringan tertentu diperlukan screw conveyor, sedangkan untuk membawa material yang vertikal (dari bawah ke atas) diperlukan bucket elevator. Maka dari itu penggunaan bucket elevator sangatlah dominan pada sistem transportasi yang ada di industri pakan ternak yang mana fungsinya sebagai pembawa material dari bawah keatas, oleh karena itu perhatian ekstra terhadap elevator sangat diperlukan tanpa melupakan mesin-mesin lainnya [1].

Dalam sistem transportasi dan pen-distribusian material banyak sekali masalah yang muncul khususnya pada unit elevator. Masalah-masalah yang muncul antara lain adalah belt elevator sering kendor, sobek atau putus, disebabkan pemakaian yang sudah lama dan kondisinya sudah melar, sehingga mengakibatkan drum putar bagian atas elevator tidak dapat berputar dengan normal dan pendistribusian material dari chain conveyor menuju elevator menjadi terhambat. Dengan kondisi tersebut maka penumpukan material akan terjadi diantara chain coveyor dan elevator [2].

Dengan memanfaatkan kondisi tersebut dipasanglah sensor limit switch yang berfungsi untuk mematikan kontrol proses pendistribusian material jika terjadi penumpukan material. Akan tetapi pemasangan sensor limit switch mempunyai beberapa kelemahan diantaranya material harus dalam kondisi menumpuk agar bisa mendorong sensor tersebut sehingga berdampak material akan keluar dan tumpah dari jalur distribusi dan berdampak terganggunya sistem produksi dimana efisiensi produksi menurun serta down time mesin meningkat, dikarenakan belt elevator yang kendor tanpa diketahui lebih awal penyebabnya [3][4].

Dari permasalahan tersebut maka dirancang alat kontrol deteksi dini keregangan belt elevator dengan menggunakan sensor speed monitor. Prinsip kerja sensor tersebut mendeteksi putaran suatu obyek, sesuai setting tertentu. Jika sensor tersebut mendeteksi adanya putaran lebih cepat atau lambat dari setting awal, maka sensor tersebut akan menghasilkan keluaran tegangan DC.

Dengan memanfaatkan putaran drum putar bawah elevator yang menjadi lambat jika belt elevator kendor, maka akan lebih efisien jika dipasang sensor speed monitor untuk mendeteksi putaran drum tersebut, sehingga keregangan belt elevator dapat diketahui lebih pasti dan lebih awal yang dapat berpotensi mengurangi downtime proses produksi [5].

\section{STUDI PUSTAKA}

\subsection{PLC CP1E - E30DRA (Omron)}

Programmable Logic Controller atau PLC, merupakan sebuah alat yang digunakan untuk menggantikan rangkaian sederetan relay yang dijumpai pada sistem kontrol proses konvensional. Sedangkan manfaat atau keuntungan dari kontrol PLC dibanding dengan sistem konvensional antara lain jumlah kabel yang dibutuhkan bisa berkurang $80 \%$, konsumsi daya lebih rendah, fungsi diagnostik dan cara pendeteksian kesalahan mudah dan cepat, jika terjadi penambahan pada sistem PLC mudah di-lakukan hanya dengan perubahan atau penggantian program pada memori, penggunaan I/O yang cukup banyak [6]. 


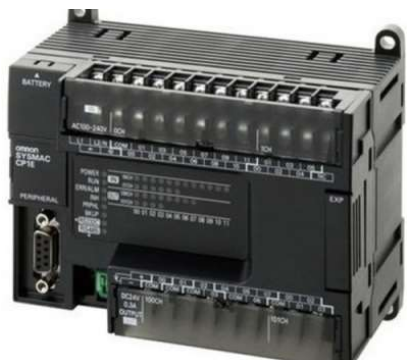

\section{Gambar 2.1 PLC CP1E E30DRA (Omron)}

PLC sesungguhnya merupakan sistem mikro-kontroller khusus untuk industri, adapun elemen-elemen dasar / komponen-komponen dasar PLC antara lain unit prosesor atau central processing unit (CPU), unit catu daya, perangkat pemrograman, unit memori dan bagian masukan dan keluaran.

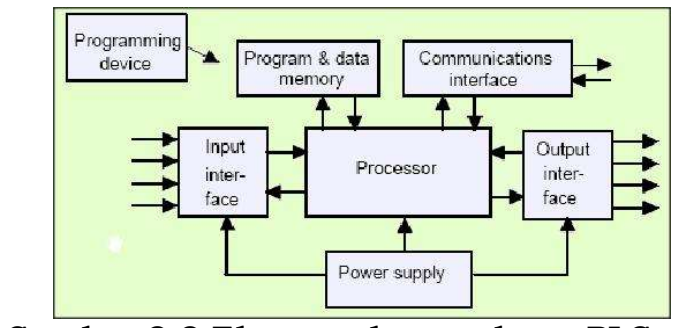

\section{Gambar 2.2 Elemen-elemen dasar PLC}

\subsection{Sensor Proximity ( Speed Monitor)}

Sensor ini memanfaatkan medan electro-magnetic untuk mendeteksi benda logam yang ada didekatnya. Secara sederhana inductive proximity hanya sensor switch yang memberikan logika true jika mendeteksi logam di dekatnya tapi ada juga jenis yang membutuhkan pulsa artinya sensor ini harus men-deteksi object (logam) berulang-ulang kali agar dapat menghasilkan pulsa dengan nilai frekuensi yang sama atau lebih besar dari setting frekuensi thresholdnya baru kemudian dia akan memberikan logika 1, sensor jenis inilah yang biasanya dipakai pada belt conveyor. Inductive proximity ada yang dua kabel ada juga yang tiga kabel ada yang 24 VDC ada juga yang 220 VAC, jadi kembali lagi tergantung kebutuhan kita dalam pemakaiannya [5].

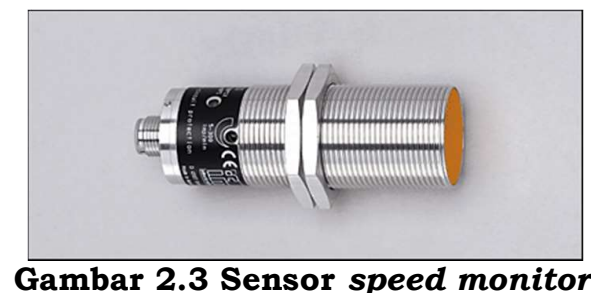

\subsection{Relay}

Prinsip kerja relay adalah komponen elektronika berupa saklar elektronik yang digerakkan oleh arus listrik. Secara prinsip, relay merupakan tuas saklar dengan lilitan kawat pada batang besi (solenoid) di dekatnya. Ketika solenoid dialiri arus listrik, tuas akan tertarik karena adanya gaya magnet yang terjadi pada solenoid sehingga kontak saklar akan menutup. Pada saat arus dihentikan, gaya magnet 
akan hilang, tuas akan kembali ke posisi semula dan kontak saklar kembali terbuka [7].
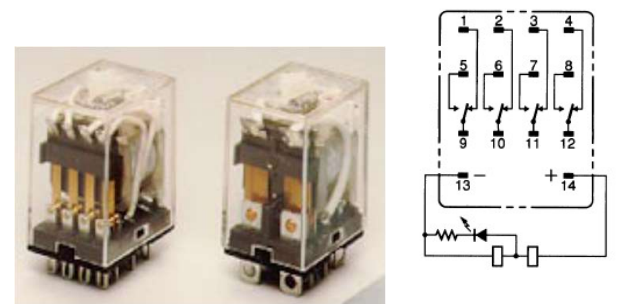

Gambar 2.4 Relai dan kontak relai

\subsection{Belt dan Bucket elevator}

Belt yang digunakan pada elevator adalah berbahan karet dengan empat lapisan. Belt berbahan karet mempunyai kelebihan mudah dalam pemasangan, usia pemakaian lebih lama. Bucket berfungsi sebagai tempat material untuk dikirim ke atas bagian elevator.

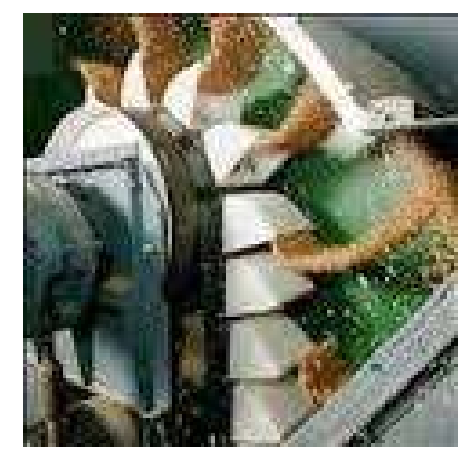

Gambar 2.5 Belt dan bucket elevator

\subsection{Rotasi ( RPM )}

Kecepatan putaran ini diukur oleh banyaknya putaran per satuan waktu. Untuk rotasi mesin yang berputar lebih cepat dari rotasi bumi,maka kita memakai satuan rotasi per menit (RPM).

Pada alat yang akan dibuat pengukuran rotasi sangat diperlukan untuk menetukan putaran tiap-tiap motor. Penggunaan gear ratio akan mengakibatkan putaran menjadi turun dan naik. Rumus yang digunakan untuk metode gear ratio adalah sebagai berikut:

$$
N 1 x z 1=N 2 x z 2
$$

Dimana:

N1 : Putaran input

Z1 : Teeth gear input

N2 : Putaran output

\section{$\mathbf{2 . 5}$ Motor DC}

Prototipe elevator ini tidak memerlukan motor dengan daya yang besar, karena kerja dari elevator ini tidak digunakan secara maksimal, motor DC dengan daya kecil sudah cukup mampu digunakan untuk menjalankan elevator ini. Jenis motor yang digunakan adalah motor 24 VDC, karena jenis motor ini mempunyai torsi yang cukup kuat dengan rentang kerja motor tegangan 3-24 VDC. 


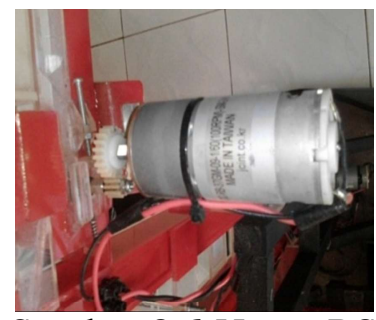

Gambar 2.6 Motor DC

Untuk suplay motor DC digunakan tegangan input 24 VDC, pada putaran kecepatan motor digunakan motor yang sudah terpasang dengan gear box dengan harapan didapat torsi dan kecepatan motor yang sesuai [8].

\section{METODE}

\subsection{Perancangan Alat Keseluruhan}

Secara umum perancangan sistem yang akan dibuat dapat dilihat pada blok diagram sistem. Hal ini dilakukan untuk mempermudah pemahaman tentang cara kerja masing-masing alat. Perancangan seperti ditunjukkan dalam gambar 3.1 :

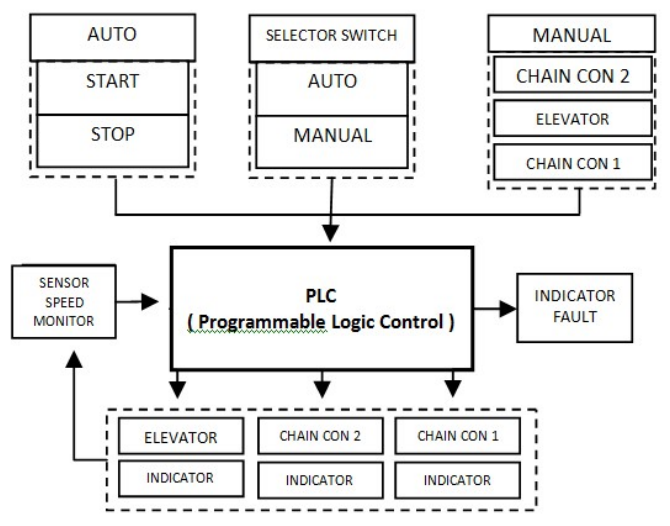

Gambar 3.1 Blok diagram system

Dari diagram blok diatas dapat dijelaskan prinsip kerja sistem sebagai berikut: Pada switch manual berfungsi sebagai langkah awal untuk menseting belt elevator. Switch auto untuk menjalankan keseluruhan sistem setelah elevator di set rpmnya. Tombol reset berfungsi untuk mengem-balikan ke sistem awal, pada saat belt elevator sudah diperbaiki jika terjadi keregangan belt. Tombol start untuk chain conveyor 2 sebagai tombol untuk menjalankan chain conveyor 2 pada kondisi manual. Tombol start elevator untuk menjalankan elevator pada kondisi manual untuk mengatur kekencangan belt. Tombol start untuk chain conveyor 1 sebagai tombol untuk menjalankan chain conveyor 1 pada kondisi manual. Inputan sensor berfungsi sebagai konfirmasi ke PLC mendeteksi putaran dari drum atas elevator. Inputan run berfungsi sebagai konfirmasi ke PLC bahwa elevator sudah jalan. Output elevator dari PLC untuk menggerakkan kontak dari relay dan menjalankan motor elevator. Output chain conveyor 1 sebagai konfirmasi ulang dari PLC untuk menggerakkan kontak relay indikator chain conveyor 1.

Output chain conveyor 2 sebagai konfirmasi ulang dari PLC untuk mengerakkan kontak relay indikator chain conveyor 2. Output alarm sebagai indikator bahwa belt 
elevator sedang mengalami kerusakan karena putaran tidak sesuai setingan. Berikut adalah sketsa dari mekanisme alat yang akan dibuat:

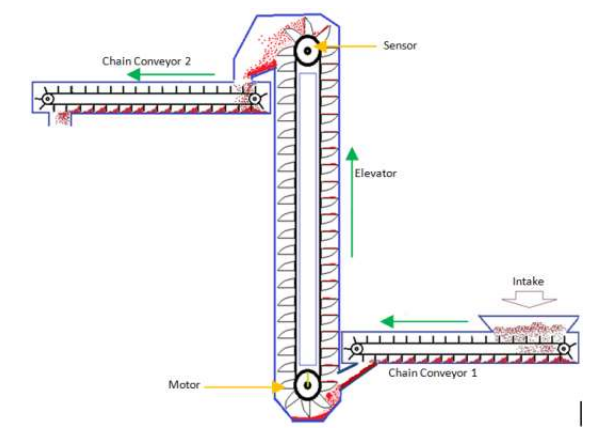

Gambar 3.2 Sketsa mekanisme alat

\subsection{Perancangan Software}

Sistem ini memiliki 9 input yaitu: manual, auto, reset, chain conveyor 2, elevator, chain conveyor 1, runing elevator, sensor rpm, reset alarm dan 10 output, yaitu: elevator, indicator elevator, chain conveyor 1, indicator chain conveyor 1, chain conveyor 2, indicator chain conveyor 2, indicator fault. Selanjutnya masing-masing input dan output tersebut dihubungkan dengan alamat I/O pada PLC. Penentuan I/O ini sangat penting sekali didalam merancang sebuah sistem, bahkan penentuan jenis sensor sangat berpengaruh pada sistem otomatisasi. Pengalamatan input ditunjukkan pada tabel 3.1 sedangkan pengalamatan output ditunjukkan pada tabel 3.2

Tabel 3.1 Pengalamatan Input

\begin{tabular}{|c|c|c|}
\hline NO. & ALAMAT & INPUT \\
\hline 1 & 0.00 & Manual \\
\hline 2 & 0.01 & Auto \\
\hline 3 & 0.02 & Start Auto \\
\hline 4 & 0.03 & Stop Auto \\
\hline 5 & 0.04 & Output Sensor \\
\hline 6 & 0.05 & Manual Conveyor 2 \\
\hline 7 & 0.06 & Manual Elevator \\
\hline 8 & 0.07 & Manual Converor 1 \\
\hline 9 & 0.08 & Reset Alarm \\
\hline
\end{tabular}

Tabel 3.2 Pengalamatan output

\begin{tabular}{|c|c|c|}
\hline NO. & ALAMAT & OUTPUT \\
\hline 1 & 100.00 & Chain Conveyor 2 \\
\hline 2 & 100.01 & Elevator \\
\hline 3 & 100.02 & Sensor SpeedMon \\
\hline 4 & 100.03 & Chain Conveyor 1 \\
\hline 5 & 100.04 & Buzzer Alarm \\
\hline 6 & 100.05 & H 1 Auto Stop \\
\hline 7 & 100.06 & Indicator Chain Con 2 \\
\hline 8 & 100.07 & Indicator Elevator \\
\hline 9 & 100.08 & Indicator Chain Con 1 \\
\hline 10 & 100.09 & H2 Auto Start \\
\hline
\end{tabular}

Agar unit PLC dapat berjalan, dibutuhkan ladder diagram yang dapat dibuat pada software CX-One $v 9.2$ dan berikut langkah pembuatannya: 


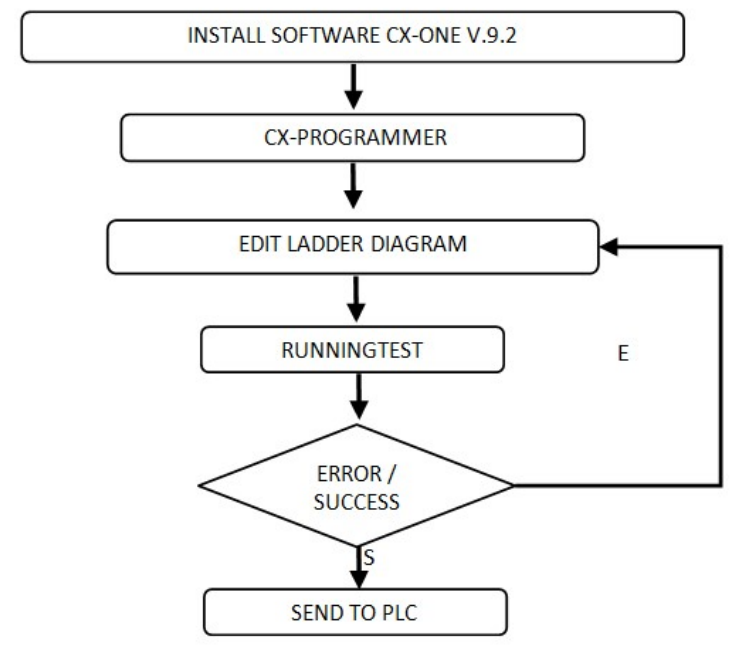

Gambar 3.3 Flowchart pembuatan program

\subsection{Perancangan Hardware}

\subsubsection{Hubungan PLC dengan sensor}

Sensor IFM DI503A berfungsi untuk mendeteksi clock pada elevator, untuk menghitung jumlah putaran belt elevator per menit. Sensor yang digunakan adalah sensor Speed monitor. Sensor ini memanfaatkan medan electro-magnetic untuk mendeteksi benda logam yang ada didekatnya. Secara sederhana inductive proximity hanya sensor switch yang memberikan logika true jika mendeteksi logam di dekatnya tapi ada juga jenis yang membutuhkan pulsa artinya sensor ini harus mendeteksi object (logam) berulang-ulang kali agar dapat menghasilkan pulsa dengan nilai frekuensi yang sama atau lebih besar dari seting frekuensi thresholdnya baru kemudian dia akan memberikan logika 1 [9].

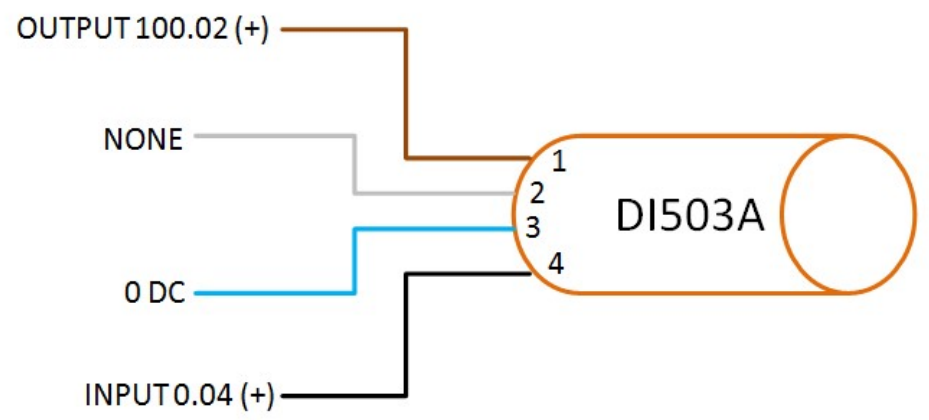

Gambar 3.4 Skema Sensor IFM DI503A

\subsubsection{Hubungan antar PLC dengan Motor}

Prototipe elevator ini tidak memerlukan motor dengan daya yang besar, karena kerja dari elevator ini tidak digunakan secara maksimal, motor DC dengan daya kecil sudah cukup mampu digunakan untuk menjalankan elevator ini. Jenis motor yang digunakan adalah motor 24 VDC \pm 100 rpm, karena jenis motor ini mempunyai torsi yang cukup kuat dengan rentang 
kerja motor tegangan 3-24 VDC. Peran motor disini untuk menggerakkan chain conveyor 1, 2 serta elevator sebagai obyek utama. Pada gambar dibawah ditunjukan hubungan output PLC dengan motor:

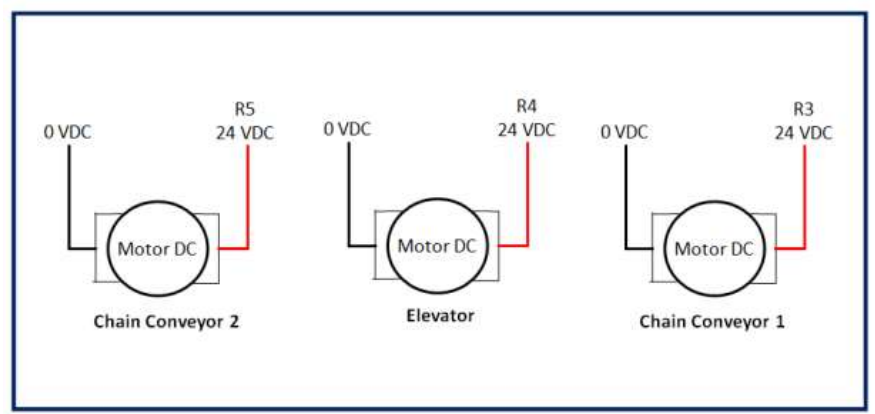

\section{Gambar 3.5 Hubungan output PLC ke masing-masing motor}

\subsubsection{Cara Kerja Rancangan Sistem}

Dengan output putaran gearbox elevator adalah $\pm 97 \mathrm{rpm}$ pada posisi drum bagian atas, sementara putaran drum bawah didapat sebesar $\pm 98 \mathrm{rpm}$.

1. Cara kerja chain conveyor dan elevator untuk sistem start stopnya dengan menggunakan dua tombol untuk on/off-nya dalam mode auto.

2. Chain conveyor 2 akan bekerja terlebih dahulu beberapa detik, kemudian elevator berputar, jika tidak ada penurunan rpm, maka conveyor 1 akan bekerja.

3. Saat tombol on/off ditekan pertama kali maka motor akan bekerja untuk beberapa saat sambil menunggu feedback dari output masuk ke input kontrol, jika dalam waktu 3 detik feedback tidak mengirim signal maka output motor akan mati.

4. Lakukan fungsi setting dengan tombol-tombol input mode manual yang sudah disediakan, tujuannya adalah untuk mencocokkan antara actual dengan setting bilamana diperlukan.

5. Jika putaran drum elevator bagian bawah $\leq \pm 95 \mathrm{rpm}$, maka sensor akan memberikan signal ke input PLC dan output PLC akan mengeluarkan signal untuk memutuskan chain conveyor serta memberikan signal alarm pada elevator (alarm fault).

6. Perbaiki terlebih dahulu kekencangan belt elevator dengan mencoba manual putaran elevator saja.

Sebelum dilakukan reset maka sistem tidak akan jalan, fungsi reset akan bekerja jika keadaan elevator sudah diperbaiki. Artinya putaran atas harus sesuai dengan setting ideal yaitu $\geq 98 \mathrm{rpm}$.

\section{HASIL DAN PEMBAHASAN}

\subsection{Pengujian Sensor Speed Monitor}

Pengujian dilakukan untuk menetukan jarak sensor ke obyek putaran dengan tepat, mengukur arus dan tegangan keluaran dari sensor jika mendeteksi adanya perubahan RPM pada drum putar atas elevator. 
Tabel 4.1 Pengukuran jarak sensor dengan obyek

\begin{tabular}{|l|l|l|}
\hline No. & $\begin{array}{l}\text { Jarak sensor } \\
\text { dengan obyek }\end{array}$ & $\begin{array}{l}\text { Pembacaan } \\
\text { ON / OFF }\end{array}$ \\
\hline 1 & $1 \mathrm{~mm}$ & ON \\
\hline 2 & $2 \mathrm{~mm}$ & ON \\
\hline 3 & $3 \mathrm{~mm}$ & ON \\
\hline 4 & $4 \mathrm{~mm}$ & ON \\
\hline 5 & $5 \mathrm{~mm}$ & ON \\
\hline 6 & $6 \mathrm{~mm}$ & ON \\
\hline 7 & $7 \mathrm{~mm}$ & ON \\
\hline 8 & $8 \mathrm{~mm}$ & ON \\
\hline 9 & $9 \mathrm{~mm}$ & ON \\
\hline 10 & $10 \mathrm{~mm}$ & OFF \\
\hline
\end{tabular}

Pengukuran tegangan sensor dilakukan dengan cara menghubungkan multimeter secara parallel dengan rangkaian beban, data diambil saat kondisi aktif dimana sensor mendeteksi putaran drum atas elevator dan kondisi putaran dibawah batas seting. Tabel dibawah merupakan data hasil pengukuran:

Tabel 4.2 Pengukuran tegangan sensor

\begin{tabular}{|l|l|l|l|}
\hline \multirow{3}{*}{$\begin{array}{l}\text { Hasil } \\
\text { pengukuran }\end{array}$} & $\begin{array}{l}\text { Input } \\
\text { RPM }\end{array}$ & $\begin{array}{l}\text { Arus input } \\
\text { (A) }\end{array}$ & $\begin{array}{l}\text { Arus output } \\
\text { (A) }\end{array}$ \\
\cline { 2 - 4 } & High & 0.06 & 0.05 \\
\cline { 2 - 4 } & Low & 0.01 & 0.00 \\
\hline
\end{tabular}

Tabel 4.3 Pengukuran arus sensor

\begin{tabular}{|l|l|l|l|}
\hline \multirow{4}{*}{$\begin{array}{l}\text { Hasil } \\
\text { pengukuran }\end{array}$} & $\begin{array}{l}\text { Input } \\
\text { RPM }\end{array}$ & $\begin{array}{l}\text { Tegangan } \\
\text { input VDC }\end{array}$ & $\begin{array}{l}\text { Tegangan } \\
\text { output VDC }\end{array}$ \\
\cline { 2 - 4 } & High & 23.9 & 22.8 \\
\cline { 2 - 4 } & Low & 24 & 0.02 \\
\hline
\end{tabular}

\subsection{Pengujian Tiap Bagian}

Pada alat ini mempunyai tiga bagian atau tahap aliran material agar sampai tujuan, yaitu melalui chain conveyor 1 beserta intake, elevator sebagai obyek utama, dan chain conveyor 2 sebagai keluaran dari elevator. Untuk menaikan dan menurunkan putaran digunakan metode gear ratio sebagai berikut.

\subsubsection{Chain conveyor 1}

Chain con 1 menggunakan motor DC 24V dengan pengukuran rotasi 118rpm. Dikarenakan ketiga bagian dari alat ini memakai 3 buah motor yang sama, maka untuk menurunkan putaran pada chain con 1 digunakan gear ratio sebagai berikut:

Teeth gear input $(Z 1) \quad: 20$

Teeth gear output $(Z 2) \quad: 50$

Putaran input (N1) : 118

Putaran output (N2) :

Dengan menggunakan rumus $N 1 * Z 1=N 2 * Z 2$ didapatkan:

$\mathrm{N} 1 * \mathrm{Z} 1=\mathrm{N} 2 * \mathrm{Z} 2$

$118 * 20=\mathrm{N} 2 * 50$

$2360=\mathrm{N} 2 * 50$

N2 $\quad=2000: 50=47.2$

Gear ratio yang didapatkan $\mathrm{N} 1 ; \mathrm{N} 2=118 ; 47$ 
Putaran pada chain conveyor 1 didapatkan $\pm 47 \mathrm{rpm}$.

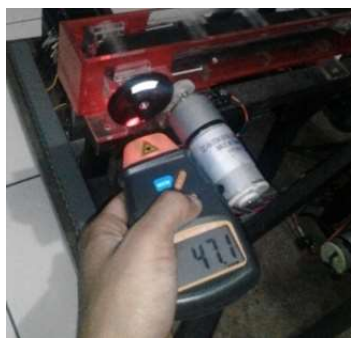

\section{Gambar 4.1 Hasil pengukuran RPM chain conveyor 1}

Sedangkan pengukuran nilai arus pada motor chain con 1 didapatkan sebesar $\pm 0.13 \mathrm{~A}$.

\subsubsection{Elevator}

Agar tidak terjadi penumpukan material, putaran elevator harus sedikit lebih cepat daripada chain con 1 maka digunakan gear ratio sebagai berikut:

Teeth gear input $(Z 1) \quad: 20$

Teeth gear output $(\mathrm{Z} 2) \quad: 24$

Putaran input (N1) : 118

Putaran output (N2) :

Dengan menggunakan rumus $N 1 * Z 1=N 2 * Z 2$ didapatkan:

$\mathrm{N} 1 * \mathrm{Z} 1=\mathrm{N} 2 * \mathrm{Z} 2$

$118 * 20=\mathrm{N} 2 * 24$

$2340=\mathrm{N} 2 * 24$

N2 $\quad=2340: 24=98.3$

Gear ratio yang didapatkan N1; N2 = $118 ; 98$

Putaran pada elevator didapatkan \pm 98rpm.

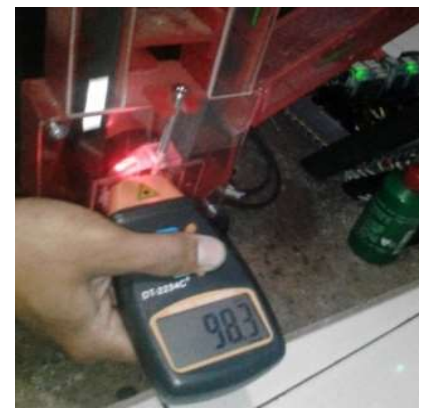

Gambar 4.2 Hasil pengukuran RPM elevator.

Sedangkan pengukuran nilai arus pada motor elevator didapatkan sebesar \pm $0.13 \mathrm{~A}$.

\subsubsection{Chain conveyor 2}

Chain con 2 menggunakan motor DC 24V dengan pengukuran rotasi $115 \mathrm{rpm}$. Dikarenakan ketiga bagian dari alat ini memakai 3 buah motor yang sama, maka untuk menaikkan putaran pada chain con 2 digunakan gear ratio sebagai berikut:

Teeth gear input $(Z 1) \quad: 20$

Teeth gear output $(\mathrm{Z} 2) \quad: 9$ 


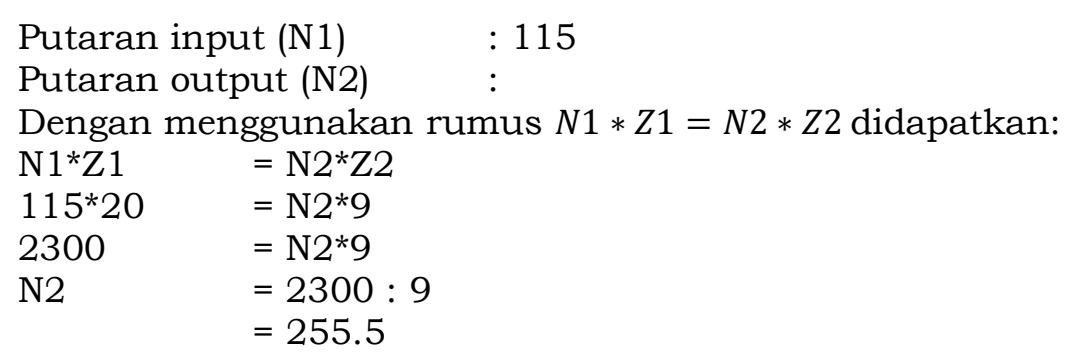

Gear ratio yang didapatkan $\mathrm{N} 1 ; \mathrm{N} 2=115 ; 255$

Putaran pada chain conveyor 2 didapatkan $\pm 255 \mathrm{rpm}$.

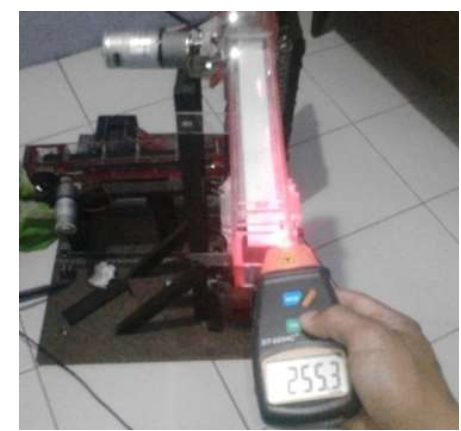

\section{Gambar 4.3 Hasil pengukuran RPM chain conveyor 2}

Sedangkan pengukuran nilai arus pada motor elevator didapatkan sebesar $\pm 0.12 \mathrm{~A}$.

Setelah melakukan 3 pengujian bagian didapatkan RPM keseluruhan sistem sebagai berikut:

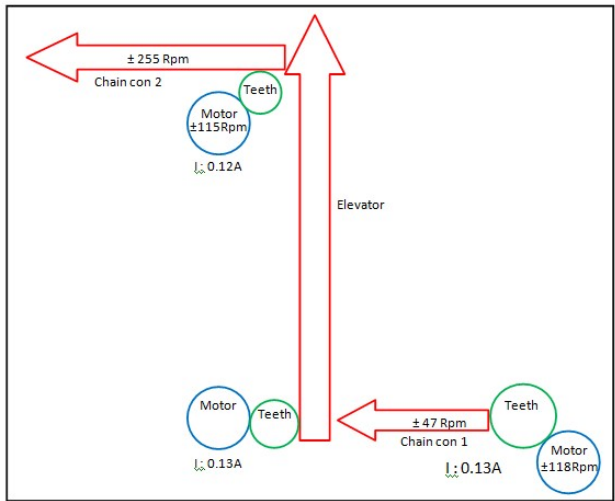

\section{Gambar 4.4 RPM dan arus motor keseluruhan system}

Dalam proses distribusi material setiap perpindahan dari satu unit ke unit selanjutnya akan berpotensi tertumpuknya material jika salah satu unit mengalami masalah atau gangguan. Oleh karena itu standart minimal agar proses distribusi tidak mengalami gangguan maka putaran motor setiap unit haruslah sama nilainya. Dari prinsip kerja inilah maka sistem kerja alat ini dibuat lebih aman untuk menekan potensi terjadinya penumpukan seminimal mungkin dengan cara mengubah kecepatan putaran motor tiap unit. Unit paling akhir dalam menerima material harus mempunyai kecepatan putar paling tinggi daripada unit sebelumnya.

Dari pengujian diatas maka chain con 2 mempunyai putaran $\pm 255 \mathrm{rpm}$, sedangkan unit sebelumnya yaitu elevator mempunyai putaran sebesar $\pm 98 \mathrm{rpm}$, dan unit pertama yaitu chain con 1 mempunyai putaran sebesar $\pm 47 \mathrm{rpm}$. 
Dengan system ini, maka potensi terjadinya penumpukan material disetiap perpindahan unit dapat diminimalisir sekecil mungkin.

\subsection{Pengujian Gangguan Belt Elevator}

Untuk menguji keregangan belt digunakan tuas penurun jarak drum atas dan bawah elevator. Jika jarak kedua sumbu as drum semakin dekat, maka keregangan belt juga akan berpengaruh dan berakibat drum putar atas mengalami slip dan sensor akan membaca putaran menurun.

Prinsip kerja sebagai berikut:

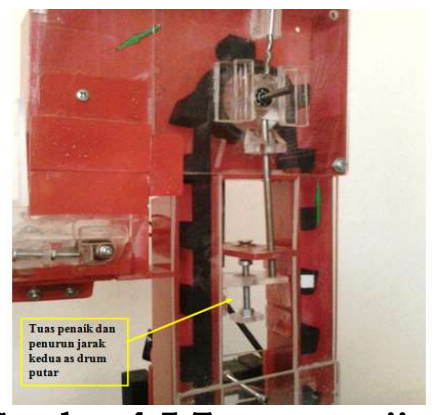

Gambar 4.5 Tuas pengujian

Pada pengujian deteksi rpm pada elevator dengan membandingkan putaran as drum atas dengan putaran as drum bawah menggunakan alat pengukur putaran (Tachometer).

1. Selector switch pada posisi manual untuk menjalankan elevator saja.

2. Belt elevator diposisikan mengencang agar tidak terjadi slip pada drum putar atas yang berakibat elevator berhenti berputar.

3. Sensor mendeteksi rpm as drum elevator

4. Gangguan diberikan dengan cara memperpendek jarak kedua sumbu as drum putar elevator.

5. Jika putaran drum atas elevator tidak sesuai setting awal maka indikator alarm akan aktif dan mematikan keseluruhan sistem

Dengan langkah diatas maka didapatkan data sebagai berikut:

Tabel 4.4 Pengujian keregangan belt elevator

\begin{tabular}{|l|l|l|l|l|}
\hline No. & $\begin{array}{l}\text { Jarak As Drum atas } \\
\text { dan bawah }\end{array}$ & $\begin{array}{l}\text { RPM } \\
\text { Drum bawah }\end{array}$ & $\begin{array}{l}\text { RPM } \\
\text { Drum atas }\end{array}$ & $\begin{array}{l}\text { Elevator } \\
\text { run/stop }\end{array}$ \\
\hline 1 & $689 \mathrm{~mm}$ & 98.3 & 97.3 & Run \\
\hline 2 & $687 \mathrm{~mm}$ & 98.3 & 97.3 & Run \\
\hline 3 & $686 \mathrm{~mm}$ & 98.3 & 97.3 & Run \\
\hline 4 & $685 \mathrm{~mm}$ & 98.3 & 97.3 & Run \\
\hline 5 & $684 \mathrm{~mm}$ & 98.3 & 95.3 & Run \\
\hline 6 & $683 \mathrm{~mm}$ & 98.3 & 94.3 & Stop \\
\hline
\end{tabular}

Dari data diatas maka dapat disimpulkan bahwa keregangan belt elevator dapat berjalan normal dengan batas antara drum atas dan bawah minimal berjarak $684 \mathrm{~mm}$. Sedangkan untuk batas putaran drum atas agar tidak terjadi alarm sensor minimal $\geq 95 \mathrm{rpm}$. 


\subsection{Pengujian Flow Material}

Pemilihan material berdasarkan ukuran unit keseluruhan alat ini dan ukuran bucket elevator agar dapat mendistribusikan material tanpa ada kendala. Di cari serbuk biji sebagai material dengan karakter tidak terlalu berat dan berbentuk bulat. Dilakukan beberapa percobaan dengan 3 ukuran material yang berbeda.

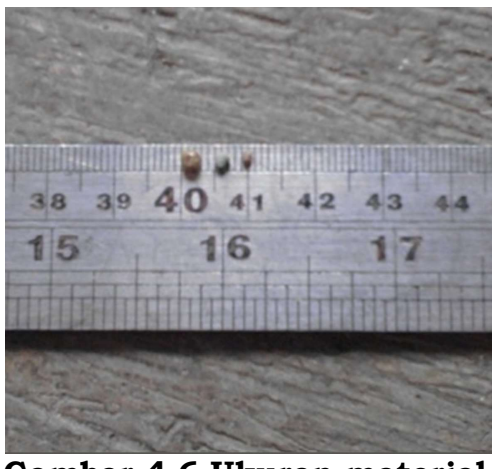

Gambar 4.6 Ukuran material

Hasil pengukuran ketiga jenis material ini didapatkan ukuran mulai dari $1 \mathrm{~mm}, 2 \mathrm{~mm}$, dan $3 \mathrm{~mm}$. Untuk mengetahui material mana yang dapat digunakan dilakukan percobaan sebagai berikut:

- Percobaan material ukuran $1 \mathrm{~mm}$

Dalam percobaan material ukuran ini tidak dapat di distribusikan dengan lancar pada bagian chain conveyor 1 karena desain jarak sirip pendorong dengan dasar chain berukuran sama $\pm 1 \mathrm{~mm}$. Sedangkan pada elevator dan chain con 2 tidak mengalami masalah.

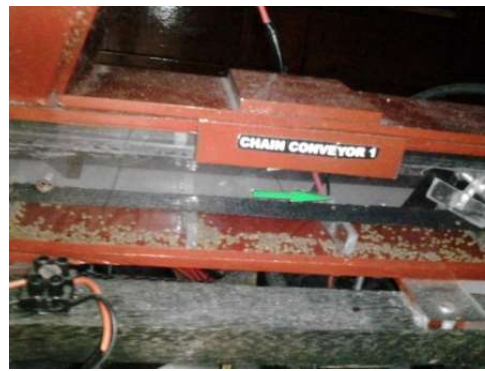

Gambar 4.7 Material sisa di unit chain con 1

- Percobaan material ukuran $2 \mathrm{~mm}$

Dalam percobaan material ukuran ini dapat di distribusikan dengan lancar pada bagian chain conveyor 1 karena desain jarak sirip pendorong dengan dasar chain berukuran lebih kecil dari material $\pm 1 \mathrm{~mm}$. Sedangkan pada elevator dan chain con 2 tidak mengalami masalah.

- Percobaan material ukuran 3mm

Dalam percobaan material ukuran ini dapat di distribusikan dengan lancar pada bagian chain conveyor 1 karena desain jarak sirip pendorong dengan dasar chain berukuran lebih kecil dari material $\pm 1 \mathrm{~mm}$. Pada elevator mengalami masalah karena sering terjepit diantara ujung bucket elevator dengan dinding dan terjepit kedalam alas bucket mengakibatkan jarak bucket lebih maju dan tersumbat di dinding elevator. 


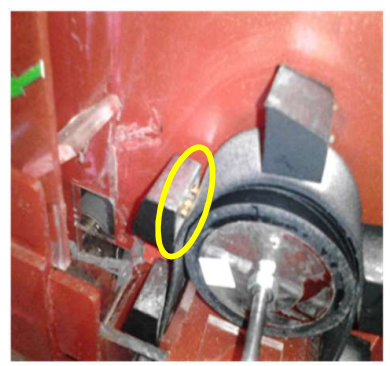

Gambar 4.8 Material menghambat laju bucket elevator

\subsection{Pengujian Keseluruhan Sistem}

Pengujian sistem secara keseluruhan bertujuan untuk mengetahui safety keregangan belt elevator berdasarkan putaran drum dapat berfungsi sesuai tujuan awal mulai dari kontrol PLC secara keseluruhan, chain con 1, elevator, chain con 2, gangguan belt elevator sampai selesai.

Pengujian alat dilakukan secara total meliputi sistem dari alat tersebut serta kecocokan sistem dengan alat yang dibuat beserta pengujian software dan pengujian hardware.

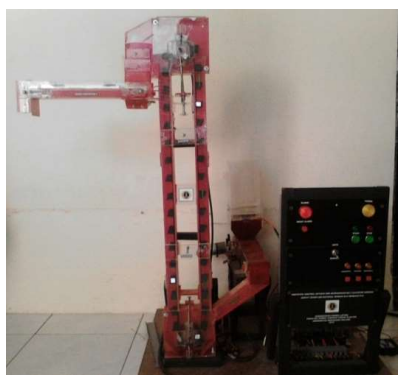

Gambar 4.9 Prototipe keregangan belt elevator.

\subsubsection{Alur proses}

Pada pengujian hardware mencakup pengujian rangkaian keseluruhan mulai dari chain con 1, sensor deteksi RPM pada elevator, dan chain con 2. Prosedur pengujian dilakukan sebagai berikut:

1. Tekan tombol start dalam mode auto sebagai langkah awal menjalankan program

2. Chain conveyor 2 akan berjalan terlebih dahulu untuk membersihkan material yang ada agar tidak terjadi penumpukan material.

3. Selang sekian detik maka elevator akan berjalan dan sensor akan mendeteksi putaran apakah sesuai dengan batas aman yaitu $\leq 95 \mathrm{rpm}$.

4. Jika sensor sudah memberikan feedback ke PLC, maka chain conveyor 2 akan berjalan.

5. Jika semua unit sudah berjalan normal, lalu kita lakukan pengetesan keregangan belt elevator

6. Dengan menggunakan tuas penurun as drum putar atas, maka belt elevator akan mengalami keregangan.

7. Jika antara kedua as drum putar sudah mencapai jarak $\pm 685 \mathrm{~mm}$, maka belt sudah dalam kondisi renggang dan RPM mengalami penurunan dibawah 95rpm. 


\section{KESIMPULAN}

1. Disaat terjadi gangguan keregangan belt, sistem deteksi dini keregangan belt elevator berbasis PLC dapat langsung mematikan keseluruhan sistem berdasarkan perubahan nilai putaran drum atas elevator, jika telah dilakukan perbaikan keregangan belt maka putaran dapat tercapai sesuai seting standart sensor speed monitor dan sistem dapat dijalankan kembali.

2. Dengan memakai sistem gear ratio pada tiap motor penggerak, putaran chain conveyor $1 \pm 47 \mathrm{rpm}$ dengan nilai arus $0.13 \mathrm{~A}$, kemudian unit elevator dengan putaran $\pm 98 \mathrm{rpm}$ dengan nilai arus $0.13 \mathrm{~A}$, dan terakhir putaran chain conveyor 2 menjadi $\pm 255 \mathrm{rpm}$ dengan nilai arus $0.12 \mathrm{~A}$ dapat meminimalisir potensi terjadinya penumpukan material di setiap perpindahan unit distribusi.

3. Pemasangan sensor yang ideal pada alat ini berjarak $\pm 5 \mathrm{~mm}$ dari obyek putar dengan nilai tegangan output 22.8 VDC dan arus sebesar 0.05A dalam kondisi high dapat mematikan keseluruhan program jika putaran drum mengalami penurunan.

4. Belt elevator berputar normal dengan batas antara drum atas dan bawah minimal berjarak $684 \mathrm{~mm}$. Sedangkan untuk batas putaran drum atas agar tidak terjadi alarm sensor minimal $\geq 95 \mathrm{rpm}$.

\section{DAFTAR RUJUKAN}

[1] K. S. Sularso, "Dasar Perencanaan Dan Pemilihan Elemen Mesin; penerbit Pradnya Paramita," 2004.

[2] P. Mitchel, Tool and manufacturing engineers handbook: material and part handling in manufacturing, vol. 9. Society of Manufacturing Engineers, 1998.

[3] S. Herman, Industrial Motor Control Cengage Learning, 2009 chapter 11" Limit Switches. ISBN.

[4] C. R. Woodcock and J. S. Mason, Bulk solids handling: an introduction to the practice and technology. Springer Science \& Business Media, 2012.

[5] M. Kretschmar, S. Welsby, and L. Precision, "Capacitive and inductive displacement sensors," in Sensor Technology Handbook, Elsevier, 2005, pp. 193-222.

[6] F. Gunterus, Falsafah Dasar: Sistem Pengendalian Proses. Elex Media Komputindo, 1994.

[7] E. Putra, P. L. C. Agfianto, and K. Pemrograman, "Aplikasi (Omron CPM1A/CPM2A dan ZEN Programmable Relay)," Gava Media Yogyak., 2004.

[8] O. Katsuhiko and L. Edi, Teknik Kontrol Automatik. Erlangga, Jakarta, 1997.

[9] F. D. Petruzella, "Elektronik Industri," Andi Yogyak., 2001. 